\title{
Music education as a means to enhance a sense of social inclusion and empower the young in Eastern Uganda
}

Tiija Rinta Tettey

Institute of Education, University of London

\begin{abstract}
Uganda has a rich culture in music, with musical skills having traditionally been passed down orally from one generation to the next. In school, music as a subject is featured in the National Curriculum; however, its teaching varies widely from school to school. Yet, due to music playing a vital role in the culture, musical activities take place daily and musicians are regularly needed in events. Engaging in musical activities could potentially empower young Ugandans and help them with feeling socially included in their communities. The current study aimed to investigate whether music education could potentially be used as a tool to empower young people through an enhanced sense of social inclusion. In total, 125 locals in the Eastern part of Uganda participated in the study. In the first phase, 125 participants completed a survey and, in the second phase 30 participants were randomly chosen for in-depth interviews. A mixed-method approach was adapted. The findings provide evidence for a much needed enhanced musical training, consequently providing the young with employable skills. The findings further indicate that being musically active in one's community can potentially enhance feelings of social inclusion and belonging amongst young Ugandans. In the long term, improved music education in schools could result in increased feelings of belonging and wellbeing amongst the young in rural parts of Uganda.
\end{abstract}

Keywords: belonging; employment; music education; Uganda; East Africa; poverty

\section{Introduction}

Similar to other African countries, Uganda has a rich culture in music. Musical skills have traditionally been passed down orally from one generation to the next (Natuhwera, 2015). Each region in Uganda holds their own traditional music and dances predominantly played by traditional instruments (Cooke, 1997; Natuhwera, op.cit.). Despite one's socioeconomic background and the region that one is from, Ugandans are surrounded by music that is played in all cultural events and festivities (Gazemba, 2015).

Over time, it has primarily been Western explorers and academics who have recorded musical traditions in writing (Cooke, 1997). There is scarce recorded historical evidence on musical practices and the majority of research has been based on Western theoretical frameworks,

Corresponding author: Tiija Rinta Tettey (tiija.rinta@gmail.com) 
with local educationists having expressed their reservations on the misinterpretation of African culture and the function of music in Uganda (Gazemba, 2016). The same dilemma is found for social issues, such as self-perceived degree of social inclusion of the young and their perceptions on tackling unemployment (Rinta Tettey, 2018).

\section{Unemployment amongst the young}

African countries are known for their unequal division of wealth, with the luxuriously rich and the poor with scarce possessions living in the same country (Taremwa, 2017). Currently, the percentage of people living in poverty in Uganda is 19.7\%, (Namuggala, 2017a). The Government is attempting to tackle poverty and unemployment, yet new interventions are needed in order to assist the young into employment (Taremwa, op.cit.).

Uganda has the highest percentage of young people in East Africa, with approximately 80 percent of the population aged under 35 (Awiti, 2016). In sub-Saharan countries, unemployment amongst the young is a severe issue (Namuggala, 2017a; Nuwagaba, 2012; Taremwa, 2017). Primary causes for such high unemployment rate are inadequate investment in creating jobs and unsuitable skills for employment (Taremwa, op.cit.). Unemployment can also lead to risky avenues in search of income, such as sex trafficking (Taremwa, 2017). The issue of unemployment is not straightforward: a recent study revealed that a percentage of young people participate in non-formal employment, including, at times, criminal activity, perceived to be a crucial part of their lives; however, the Government has classified them as unemployed since their form of employment is not considered proper or legal (Namuggala, 2017b).

Vocational training skills have been argued to be crucial for seeking employment (Bandiera et al., 2012; Nuwagaba, 2012). However, there is a general negative attitude towards vocational training courses and, thus, there is a need for such training to be merged with mainstream education (Nuwagaba, op.cit.). Moreover, implementing entrepreneurial training in education has been found to have resulted in a greater number of the young starting their own businesses (Byabashaija, 2011; Ssempebwa, 2006).

Unemployment is particularly high in the Eastern and Western parts of the country due to discrimination amongst tribes, poorer quality of education and lack of employment opportunities (Lakuma et al., 2016). The youth have been reported to be the most affected, with individuals above the age of 25 gaining employment quicker than those under the age of 25 (Lakuma et al., op.cit.). Therefore, there is a great need for intervention for tackling unemployment amongst the young particularly in these regions.

The sectors that employ the majority of young people are farming, agriculture and education (Uganda Bureau of Statistics - UBS, 2016). It has been reported that young people who are less qualified and educated are more likely to earn an income, as they are more willing to take on work that requires minimal qualifications (unemployment rate 3.5 percent) than their peers who have attained higher education (unemployment rate 11.8 percent) (UBS, op.cit.).

\section{Social inclusion}

Social inclusion is considered to be a key element in maintaining a society with a happy and healthy population (such as in preventing high rates of unemployment) (Leary, 2008). Social inclusion is a relatively new concept, yet it has received growing interest in the policy arena, as well as in social and educational work (Dennis \&Guio, 2003; Gestrich\& Raphael, 2008; Leary, op.cit.; Molden et al., 2009; Tisdall et al., 2006). Social inclusion can be defined as 'the 
process of improving the terms of participation in society, particularly for people who are disadvantaged, through enhancing opportunities, access to resources and respect for rights' (UN, 2018, p. 21). Social exclusion, on the other hand, can be defined as 'a state in which individuals are unable to participate fully in economic, social, political and cultural life, as well as the process leading to and sustaining such a state' (UN, 2018).

One of the sustainable goals of the 2030 World Agenda as set by the United Nations is that every person should reap the benefits of prosperity and enjoy minimum standards of well-being (UN, 2018). Increased importance has been placed on the concept as it is regarded a pillar for addressing a number of social problems (such as unemployment and a high rate of crime) (European Commission, 2003; UNESCO, 2010). Furthermore, programmes and interventions have been designed for combating social exclusion and for promoting inclusion (European Commission, op.cit.; Tisdall et al., 2006). However, great differences remain amongst the population, in particular in developing countries (UNESCO, op.cit.).

Recent studies have found that a number of young Ugandans feel socially excluded from society primarily due to poverty that leads them to be unable to participate in a number of activities in their society (Bongomin et al., 2017). Poverty and unemployment have, therefore, been identified as primary factors contributing toward feeling of social exclusion for young people (Bongomin et al, op.cit.). Feelings of social exclusion can, in turn, lead the young to criminal paths, alcoholism and drugs, or simply result in them feeling worthless and depressed (Atkinson \& Marlier, 2010). Due to the negative effects of social exclusion on society as a whole, the aim of countries worldwide is to have socially inclusive societies (UN, op.cit.). Therefore, interventions are needed for battling social exclusion and enhancing social factors directly related to it, such as rates of employment (Atkinson \& Marlier, op.cit.).

There are various factors that constitute the concept of social inclusion. These have generally been divided into psychological and sociological factors that are inter-connected and influence one another (Dennis \&Guio, 2003; Frederickson \& Furnham, 2001; MacDonald \& Leary, op.cit.; Poggi, 2003; Twenge et al., 2007). Psychological factors include: motivation; feelings of loneliness; self-efficacy; anxiety; self-esteem; self-regulation; identity; development; feelings of contentment; and feelings of belongingness (Beidel et al., 1995; Crick \& Ladd, 1993; Frederickson \& Furnham, 2001; MacDonald \& Leary, 2005). Sociological factors include: social relationships and networks; group coherence and dynamics; marginalization; integration; interaction; social sharing; and enabling social relations (Crick \& Ladd, op.cit.; Poggi, 2003). Figure 1 illustrates the different factors that are reported to constitute social inclusion. 


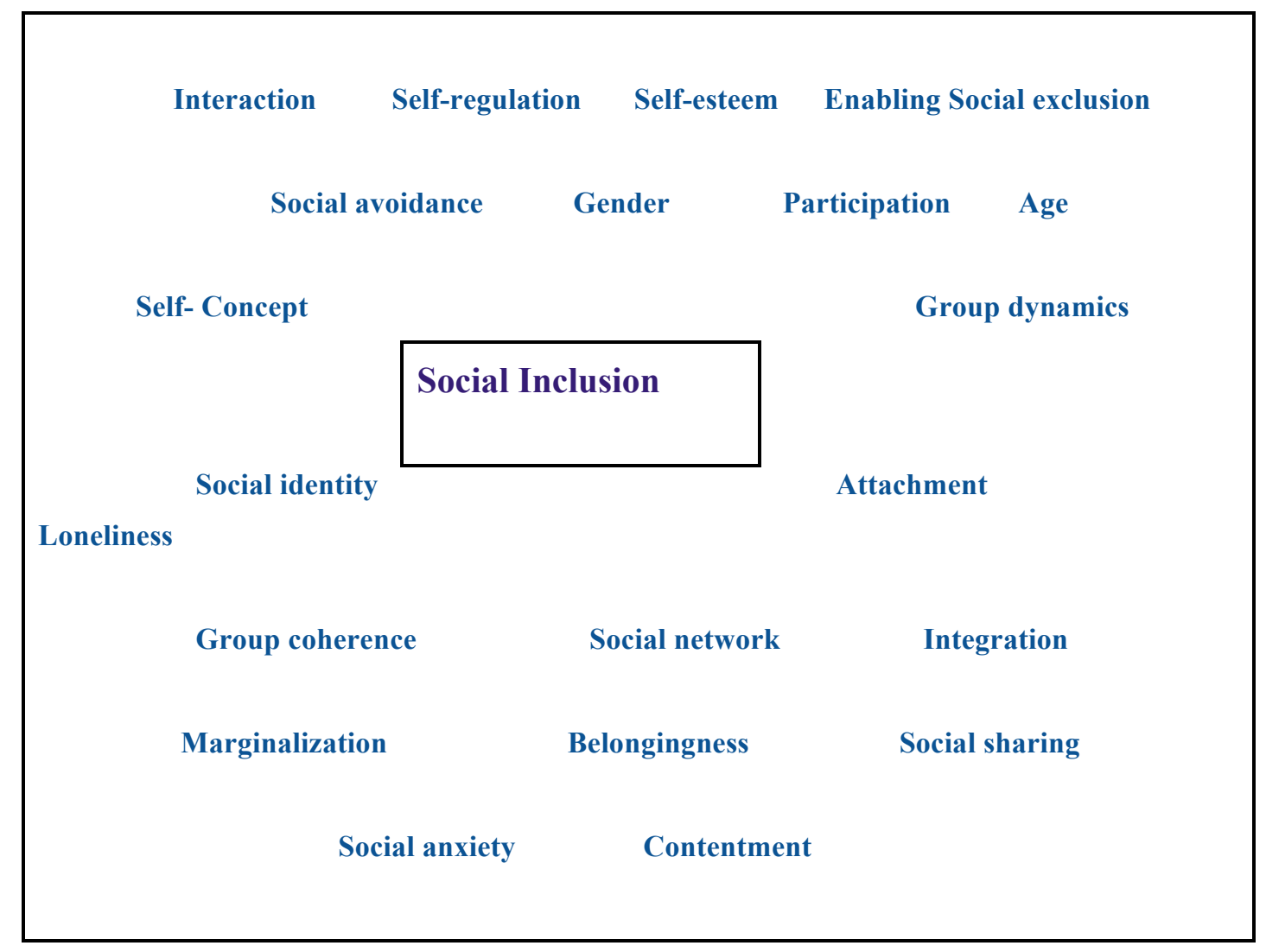

Figure 1: Elements that constitute social inclusion (Source: Rinta et al., 2011)

\section{Music industry as a form of employment}

The music industry in Uganda is vibrant and plays a strong role in the social and economic lives of the general public (Gazemba, 2015). Music is regarded a vehicle for reaching all ages in social, political and economic aspects (Natuhwera, 2015). Due to their perceived position as powerful influencers, in recent years, musicians have used their music to relay social and political messages in order to encourage social and economic change (Awiti, 2016). Since the music industry is steadily growing and attracting the younger generation, the industry could be utilized for the benefit of wider society (Propa, 2015).

The Ugandan music industry has produced internationally successful musicians and there are recording artists in the country that have become household names (Nasasira, 2016). At present, popular music appears to appeal to the general public due to its simplicity that enables individuals to participate in music making with little knowledge of music (Solomon, 2015).

Moreover, due to the rich musical culture of the country, music is performed in all cultural and religious events (such as church services, graduation and wedding parties) (Kyeyune, 2015). This indicates that a career in music could potentially be a profitable choice of self-employment amongst the young. Musicians are in high demand for parties and functions, indicating that the young could build careers in the field (Gazemba, 2015). 
Music education combined with advice on how to build a career in music could lead to a significant number of young people finding their way out of unemployment and poverty by being self-sufficient financially. Music and arts programmes in communities have been found to facilitate feelings of social inclusion in citizens, in particular amongst the young (Rinta et al., 2011). This indicates that engaging in music or other arts can enhance feelings of belonging amongst the young, consequently resulting in a reduced rate of crime and unemployment.

Figure 2: School children in music competition rehearsal in Bududa, Eastern Uganda, in 2011 (permission for publication was received from all participants; copyright @tiijarinta)

\section{Current music education system}

Formal music education introduced by European missionaries in Uganda was maintained by successive governments after the country's independence in 1962 (Kyeyune, 2015). Over the years, universities and teachers' colleges have aimed to include music in their teacher training (Kigozi, 2015). However, this is not fully realised, primarily due to the way music education is managed and positioned in formal education (Achieng' Akuno, 2009). Currently, the Government is simply committed to providing 'quality basic education and training' (MOES, 2004), with most educational activities aiming to facilitate science education, technology and skills training for employment (Achieng' Akuno, op.cit.).

Despite the newly revised primary school curriculum that has been implemented in schools since 2010 that states that performing arts (including music) should be taught in school, the teaching of music is still sporadic and varies widely from school to school (Kigozi, 2015). Moreover, music is classed under physical education and not entirely recognised as an integral part of indoor classroom education (Kigozi, 2008). Yet, music education can provide the young with useful skills for self-employment and provide them with the knowledge needed for 
founding their own businesses, thus preventing them from falling into poverty due to lack of work and enabling them to support themselves (Kigozi, 2015).

One of the main issues faced in music education is that its development is not taking place through transparent processes, with some schools being far more advanced in teaching music than others (Kigozi, 2015). Teacher training models are short of equipping teachers with the necessary musical skills required for meeting the needs of pupils (Makubuya, 1999; Rinta Tettey, 2018). Furthermore, students join teacher training programmes with limited musical backgrounds and experience and, consequently, have low levels of confidence in their ability to teach music (Kigozi, op.cit.). In general, music is perceived as an area in which teachers have a low level of teaching efficacy as a result of inadequate training, lack of music resources and the irrelevance of musical content (Kigozi, 2016). The learners' response to music as a classroom subject is primarily influenced by their own musical engagement outside the school, such as at churches or youth clubs (Kigozi, op.cit.).

In contrast to how music education is positioned at schools, parents in general are eager for their children to learn musical skills (Achieng' Akuno, 2009). A great number of parents believe that high quality music training can provide the young with essentials skills for seeking selfemployment in cultural activities and various functions (Achieng' Akuno, op.cit.). Music education is generally regarded a vital part of the education system (Natuhwera, 2015). Hence, there appears to be a need for music education to be included in mainstream education in schools more effectively (Achieng' Akuno, op.cit.). The current study aimed to investigate such a potential gap and to explore whether music education could potentially be utilized in enhancing social inclusion in Eastern Uganda.

\section{Aims of the current study}

The current study was exploratory in nature. The study intended to gather initial perceptions and opinions of locals on practical music training programmes currently in place in the Eastern part of Uganda. The specific aim of the study was to investigate whether, over time, a career in music could potentially be utilized for combating unemployment amongst the young through providing them with the needed practical musical skills for a career in music, simultaneously increasing their sense of social inclusion and belonging in their communities.

A further intention was to explore whether musical training could potentially be used a method to empower the young, provide them with a focus on their lives and subsequently assist them in feeling more socially included.

\section{Methods}

A survey and in-depth interviews on perceptions on how music could be used as a career to combat unemployment was administered to education professionals and parents of primary school children in the Eastern region of Uganda. The intention was to explore the perceptions of locals on whether and how practical musical skills training could function as a social intervention. A mixed-method, exploratory approach was adapted to the study.

In total, 125 adults participated in the study. The majority $(\mathrm{N}=85)$ of the participants worked in the field of education, with 40 being parents of primary school children. The participants lived and worked in Bududa, the Eastern part of Uganda. They were recruited by a local research team member who contacted local schools and colleges individually. The schools and colleges were selected from a list of educational establishments published by the Government. The researcher contacted all schools listed $(n=89)$. The schools and colleges selected willing 
participants from amongst their staff and from amongst parents of their pupils.

\section{Ethics}

It was made clear to all participants that any resultant data would be anonymised and neither the school nor the participants would be identified at any point. The participants were informed that data were to be kept safely on a secure server and password protected. The researcher had full Criminal Records Bureau Clearance from the UK Government and the ethical guidelines of the British Education Research Association were followed throughout the study.

\section{Survey and interviews}

A survey was conducted in the Eastern part of Uganda. The survey items were formulated on the basis of an extensive literature review (Rinta Tettey, 2018). Firstly, they were piloted with five locals that took place in January 2018. Two of the survey items were revised prior to conducting a larger scale survey. The final survey schedule can be found in Figure 3.

\section{Career in Music as a Means to Combat Unemployment amongst the Youth in Uganda?}

Thank you for taking the time to answer the following questions on how a career in music could (or couldn't) potentially be a profitable career choice for young people in Uganda - your replies are much appreciated! They will be anonymous through the research and all data will be stored in secure locations. An academic article and research report will be written on the findings for the Institute of Education University College London (UK).

1. In your opinion, could a career in music (such as playing a musical instrument in functions or at church events) currently help the young in Uganda find employment and to pave their way out of poverty?

2. In your opinion, what are the main obstacles preventing the young from pursuing a career in music?

3. What could be improved in the field of education in order for the young to be able to pursue a career in music?

4. In your opinion, are there great possibilities and number of functions frequently taking place in Uganda, in which musicians are needed and in which the young could find employment?

5. Please describe your perceptions on how music and musical training could assist in empowering the young and enhance their feelings of social inclusion.

Figure 3: The survey instrument used for data collection in the Spring of 2018 
Subsequent to the survey, 30 of the participants were interviewed more comprehensively. These individuals were selected at random from the survey sample. The survey items were used for the interview in order to gain a more comprehensive and detailed response to the research questions.

\section{Participants}

A total of 125 adults participated in the study. Of the total, 85 of the participants worked in the field of education and 40 were parents of primary school children. The sample included: 40 primary school teachers; 15 secondary school teachers; 15 Local Government Educational Officials; 15 Teacher Training professionals; and 40 parents of local primary school children.

The participants lived and worked in Bududa, the Eastern part of Uganda. They were recruited by a local research team member who contacted local schools and colleges individually. Initially, the majority of the participants were hesitant to take part in the study, as they feared that their responses would be seen in a negative light by their superiors. Therefore, the research team assured them that their responses were to be kept anonymous at all times and all data would be stored on secure computers with passwords and in secure lockers.

The sample consisted of 78 females and 47 males. They were within the age range of 21 to 64 , with the mean age of 34 . All the education professional participants had been working in the field of education for 3-38 years. They had all been residents in the Eastern region of Uganda for the majority of their lives and, thus, were familiar with the challenges faced in this part of the country. The parent participants were from a variety of backgrounds, ranging from farmers to pharmacists.

Table 1: Demographics on the education professional participants that took part in the study

\begin{tabular}{|l|l|l|}
\hline Profession & Mean Age & $\begin{array}{l}\text { Mean Years of Teaching } \\
\text { Experience }\end{array}$ \\
\hline Primary school teacher & 29 & 8 \\
\hline Secondary school teacher & 31 & 11 \\
\hline $\begin{array}{c}\text { Local Government } \\
\text { Education Professional }\end{array}$ & 38 & 34 \\
\hline Teacher Trainer & 30 & 21 \\
\hline
\end{tabular}

\section{Procedure}

An action research methodology was adopted to the fieldwork. A draft survey questionnaire was designed and initially piloted with three education professionals and two parents in Bududa in January 2018. Their responses lead to a modified version of the survey questionnaire. 
The survey was administered in primary schools and teacher training colleges in the Eastern part of Uganda. The participants were assured that all data would be kept confidential and used for the current research study only. The survey was conducted in March 2018.

The researcher went into different education settings once a week over the period of one calendar month. It took approximately 15 minutes for each participant to answer the survey questions in a quiet room. In each location, the researcher chose five participants at random to participate in a more in-depth interview that was conducted subsequent to the survey. Each interview was approximately 17 minutes of duration and was recorded with a voice recorder for data analysis purposes.

\section{Data analyses}

The data were analysed qualitatively and quantitatively. Microsoft Excel software was used in the qualitative analysis and IBM SPSS statistics (2015) was used in the quantitative analysis. Qualitative responses from the interviews and survey were transcribed and logged into Excel in order to analyse the qualitative data in a systematic manner. The frequency of emerging themes and key words were analysed, with attention paid to detail. Each response was typed out in Excel in full prior to analyses. The function of word frequency was utilized in order to identify the most reoccurring words in the responses.

Statistical analyses were used for analysing the positive and negative responses to the survey and interview questions. Spearman's Rho was calculated separately for each item. The correlations were used in order to explore any potential associations between the research items proposed in the research aims. Correlations were calculated for investigating any potential relationships between: participating in music training and enhanced feelings of social inclusion; engaging in formal music training and increased self-confidence; engagement in formal music training and level of motivation to pursue self-employment or to start your own business in music; indicated willingness to pursue formal music training and level of cultural preference for live music events and performances; and the growing demand for professional musicians and the perceived effectiveness of the current music education curriculum in schools.

Each item was scored on a 5-point Likert scale, with scores 1 and 2 indicating a negative response, 3 a neutral response and 4 and 5 a positive response. Three difference members of the research team scored each item and the scores were meaned for the purposes of the data analyses.

\section{Results}

The main findings are presented below under four broad categories that emerged from data analyses: Motivation to Pursue a Career in Music; Demand for Musicians; Improved Music Education System; and Enhanced Feelings of Social Inclusion and Belonging. Firstly, the results from the survey are reported quantitatively. Secondly, the findings from the interviews are reported qualitatively. 


\section{Motivation to pursue a career in music}

One of the primary findings was that the participants strongly believed that music training could be used as a tool to assist the young in seeking self-employment and starting their own businesses $(r=0.770, p<0.05)$. Both the education professionals and the parents stated that the young felt motivated to gain practical skills in music and to develop their music skills in order to gain employment in the field $(\mathrm{N}=125)$. This, in turn, was perceived to be a potentially effective route to preventing them from becoming unemployed and to help break the cycle of poverty. Since musicians are greatly needed for a variety of cultural and religious events and functions, being trained as a musician could provide the young with employment.

A male primary school teacher stated:

There are so many events and festivities going on all the time everywhere in the country where they always need musicians. Young people could easily seek profitable employment in such places if they were musically trained. I would change the policy on music education, because it is the major source of employment especially among the youth.

A mother of a primary school boy responded:

So many events and functions take place all the time where musicians are needed. I wish I had had a chance to learn to play a musical instrument properly so that I could play professionally. That way I would certainly have a career to focus on and some security in my life. If I had been trained in music, I could have practical skills to apply in the field.

A male teacher training professional replied:

I would think that the majority of the young would want to learn practical musical skills, in particular if there is evidence that they can bring them employment. Most young people are concerned with the prospect of unemployment and not being able to fetch a livelihood.

The more detailed responses in the interviews further highlighted the need for wider and more inclusive opportunities to pursue music education. The interviewees reported examples of innate motivation to pursue music education in their communities.

A Headteacher of a primary school stated:

There is an underlying sense of willingness to pursue music education in our school and the local community at large. There is an understanding of how music industry can provide employment to the young due to our musical culture. Schools should do more to ensure that their pupils have access to music education.

A primary school class teachers reported:

There should be more general music education included in school, because it can be costly to learn outside of school and this creates a discrepancy between those from richer backgrounds and those from poorer backgrounds. 
In general, there is a strong will amongst the young to learn music.

\section{Demand for musicians}

All of the participants $(\mathrm{N}=125)$ reported that, since the Ugandan culture is very rich in music, there is a need for professional musicians that can perform in various events and functions taking place daily. Both the education professionals and the parents regarded the music industry a potentially profitable career choice $(\mathrm{N}=125)$. Uganda has a large population and the majority of events and functions play music, with live musical performances being a preference of the nation $(\mathrm{N}=120)$. However, it was reported that the current music education system was of low standard and did not train the young proficiently for a career in music (need for improved music education system and need for enhanced music training for the young: $r=$ $0.830, p<0.05)$, resulting in a demand for professional musicians.

A female teacher training professional stated:

The current music education system does not train young people well and they lack the practical musical skills needed for pursuing a career in music. From what I have heard, there is a real lack of professional musicians across the country. Many events and functions would like to have live music played and they would like to have a choice of different styles of musics and musical instruments, but they don't the choice due to a lack of qualified musicians.

A father of a primary school girl reported:

We live in a very musical culture. Wherever we go, we hear and see music. Kids grow up singing, dancing.... Yet, the education system is such that they do not train in practical musical skills and there seems to a lack of professional musicians in many parts of Uganda, except maybe around Kampala [the capital] where there are many private music schools nowadays.

A primary school teacher replied:

We hear about many jobs in the field of music, but we can't even consider them because we haven't been trained with practical musical skills.

The in-depth interview data supported such findings. All interviewees believed that the rich musical culture could provide greatly needed employment opportunities to the young.

A local government education professional and class teacher stated:

What worries us as parents is the lack of employment opportunities out there for our children. We can all see that our musical culture could provide much needed employment for them, yet they lack the skills to pursue such careers. The school system needs to bridge this gap and this way help the young to be a part of their societies and feel included.

A primary school teacher reported:

For quite some time, we have seen the need for musicians to grow in our culture and society. There are so many events taking place on a daily basis where musicians are needed. In addition, the music industry for recording artists is growing. We can see many employment opportunities, yet our young people lack the music education needed for such work. 


\section{Improved music education system}

Amongst the participants, there was a general sense of the current music education system at primary schools needing to be improved. As reported by the majority of the respondents $(\mathrm{N}=116)$, a lack of standardized supervision, national monitoring and teacher training has resulted in music not being taught in a great number of schools and the subject remains sidelined in mainstream education. It was reported that training teachers in music skills was not adequate and that teachers in general failed to meet the needs of their students musically due to a lack of training $(\mathrm{N}=112)$ (need for enhanced teacher training and catering for music students: $r=0.811, p<0.05)$. For instance, a number of teachers were not able to play any Western musical instruments or read musical notation $(\mathrm{N}=109)$.

A male primary school teacher reported:

Although it [music] is compulsory at primary level, most teachers perceive it as waste of time since they feel that it is not examinable. They only train kids to take part in music competitions, and for music festivals.

The Director of a Primary School Teachers' Training College stated:

Music is taught mainly in preparation for music festivals and events, such as Annual General Meetings, church services amongst others. Many teachers see it as entertainment and don't place enough value on it.

A mother of a school girl reported:

We didn't learn much music in primary school nor secondary school. We just did some singing and percussions, mainly in preparation for the annual music festival and competition. The teachers only want us to take part in this competition to gain a reputation for the school. They don't place much value on the development of the students' musical skills.

The interviewees further highlighted the need for an improved music education curriculum for primary schools. From the interview data, it became evident that teachers, in general, lack the needed skills for effective music teaching at schools and that there is not a comprehensive enough primary school music curriculum in practice at present.

A teacher trainer from a local teacher training college reported:

In many schools, music is not included in the curriculum much of the time. Precedence is given to subjects such as English and Maths. Even when there is guidance on music education and a curriculum to follow, music is not always delivered. More monitoring and support is needed in this area.

A Headteacher of a primary school stated:

The current music education curriculum is not accessible to all teachers. Either they lack the skills or resources to deliver it, or they simply don't understand it.

A local education professional elaborated:

The music curriculum is not comprehensive enough and it does not assist 
locals to develop as overall musicians. This curriculum needs to be improved and we should seek advice from professionals on how to do this.

All of the participants $(\mathrm{N}=125)$ stated that they would like to change aspects of the music curriculum and its delivery in primary school. The main reason for this was that they wished for music to be compulsory at all levels of education in Uganda, in particular since their culture is extremely rich in musical traditions and since there appears to be a need for professional musicians.

A male primary school teacher responded:

I would change the music education system in Uganda. I would make music education compulsory at all levels because music is part of our cultural heritage. It plays a very significant role in the lives of people from conception, birth, growth, adolescence, adulthood, old age, death, burial and last funeral rituals.

A female teacher trainer reported:

Music should be implemented in schools better, because it is a skill that can employ many of the youth who are unemployed.

A female primary school teacher stated:

By making music compulsory to all levels of learning, the skill could be utilized to create employment as music industry employs the youth who are the majority not employed, hence music training could reduce unemployment.

The interview data highlighted that the Ministry of Education did not place a sufficient amount of importance on music education as it was not classed under compulsory subjects in school. It was argued that the Ministry of Education should be lobbied on the importance of making music education compulsory and the role it can play in creating employment for the young.

A primary school teacher stated:

The key issue here is to make politicians and those in power aware of the importance of a comprehensive music education system. The curriculum designers need to comprehend how the music industry and musical culture can create employment for the young and how this, in turn, can help solve the issue of unemployment in Uganda.

A local education professional reported:

Unfortunately, Ugandans are not used to voicing their opinions and not aware of how to go about changing their society. We need more active individuals and the support from those around us to help us lobby those in powerful positions to change the current provision of music education in schools in Uganda. 


\section{Enhanced feelings of social inclusion and belonging}

There was a strong and significant sense of belief that engaging in musical activities and being trained musically could empower the young $(r=0.950, p<0.05)$ and further enhance their feelings of social inclusion. There was a general feeling amongst the respondents that gaining practical skills in music could empower the young and build their confidence $(r=0.875, p<$ 0.05 ), leading to participation in events as musicians and subsequently enhancing their feelings of social inclusion $(\mathrm{N}=122)$.

A female primary school teacher reported:

Certainly skills training in a specific field such as music would empower the young and make them feel like they are confident in a particular field. It would give them a focus in their lives and guide them on a career path.

A male primary school teacher stated:

Feelings of belonging are essential for everyone, but in particular for young people to feel that they are part of their society. They need such feelings in order not to feel that no one cares about them and ending up on criminal pathways.

A female teacher trainer stated:

Music is such a vital part of the culture. You can hear music everywhere. We see live musical performances everywhere. Being a musician and having an important role in the society would certainly prevent negative feelings in young people and help them feel valued and included.

The data from the interviews supported such findings. There was a strong sense amongst the interviewees that, through participating in musical activities and in the culture through engaging in music, the young could be supported in feeling valued and included in their society.

A primary school teacher reported:

We have problems with youth unemployment, which can lead the youth into criminal paths or cause mental health problems such as depression or alcoholism. Taking part in musical activities and events could certainly help prevent a negative cycle of poverty and poor mental health.

A Headteacher of a primary school stated:

We need interventions in the society to combat unemployment and to prevent individuals from falling into criminal pathways. Music education could be utilized as one of those interventions.

Table 2 below shows the descriptive statistics for the variables measured in the study. The mean scores and standard deviations for the four main categories that were considered in the analyses are presented in the table. 
Table 2: Descriptive statistics for the variables measured by the survey instrument

\begin{tabular}{|l|l|l|}
\hline Variable & Mean & Standard Deviation \\
\hline Motivation to study music & 4.201 & 0.414 \\
\hline Demand for musicians & 4.443 & 0.325 \\
\hline Feelings of social inclusion & 4.817 & 0.218 \\
\hline Self-confidence & 4.678 & 0.356 \\
\hline
\end{tabular}

\section{Discussion}

Music plays a significant role in the cultural lives of Ugandans, with musical performances taking place in events and functions on a daily basis and music filling an important role in the daily lives of locals (Cooke, 1997; Gazemba, 2015; Natuhwera, 2015). Yet, the music education system in primary schools across the country is not developed to a sufficiently high standard and it lacks transparency (Kigozi, 2015; Makubuya, 1999). Vast differences can be recorded between schools as to how and whether music is taught (Kigozi, 2016; RintaTettey, 2018). A lack of national monitoring has resulted in a great number of schools not delivering music at all, with the majority of the young being exposed to music in out-of-school settings (such as churches) (RintaTettey, op.cit.).

The findings from the current study highlighted the evident discrepancy between the role of music in Ugandan culture and the perceived low standard of music education in primary schools across the country. The findings indicate that teachers are not trained to a sufficiently high standard in delivering music effectively at schools, being unable to cater for the needs of their pupils. Teacher training courses do not appear to allocate sufficient time to music education. It was reported that the majority of the teachers who do teach music in primary schools have gained their skills in their leisure time, not on their training courses.

The findings revealed an evident need for improved teacher training courses and for an improved music education curriculum in primary schools across Uganda. There is also a need for enhanced national monitoring and assessment. Specific standards and goals for each school, as well as a comprehensive primary music education curriculum, would assist teachers in delivering music once they have been provided with appropriate training.

Furthermore, the findings from the study highlighted a need for professional musicians in the country, as live musical performances can be seen in nearly all cultural events and functions (Kyeyune, 2015; Namuggala, 2017; Taremwa, 2017). Musicians are in high demand for parties and functions, indicating that the young could build profitable careers when trained musically (Gazemba, 2015; RintaTettey, 2018). This indicates that a career in music could potentially be 
a profitable career choice for self-employment amongst the young. The findings suggest that seeking employment as a musician could help break the cycle of poverty, as unemployment amongst the young is a severe issue, currently standing at $19.7 \%$ (Awiti, 2016). Through training the young with practical musical skills, they could seek employment as musicians and avoid falling into poverty.

Moreover, the participants of the current study strongly felt that, since music plays such an important part in their culture, working as a musician and being able to participate in local events as a musician could empower the young and help them feel valued, acknowledged and socially included in their localities. Recent studies have reported that a number of young Ugandans feel socially excluded from society, primarily due to poverty that leads them to be unable to participate in a number of activities in their communities (Bongomin et al., 2017). Poverty and unemployment have, therefore, been identified as the primary causes for the young to feel socially excluded (Bongomin et al., op.cit.). Feelings of social exclusion can, in turn, lead the young to criminal paths, alcoholism and drugs, or simply result in them feeling worthless due to lack of motivation (Atkinson \&Marlier, 2010). By providing the young with employable skills, such as practical music training, they can begin to feel more socially included whilst finding a fulfilling career, preventing them from falling into poverty and potentially into criminal paths.

In summary, the study highlights a need for an improved music education curriculum to be implemented in primary schools and for teachers to be trained more adequately in musical skills. In a country where a significant number of young people remain unemployed, a career in music could assist them in finding employment, empower them and help them feel socially included. The study indicates that there is a significant gap between music education practice in primary schools and the daily lives of locals.

It should be noted that the current study was of exploratory nature on a small scale. A largerscale study with a larger number of individuals would provide further evidence on the research questions. It would also be beneficial to interview professional musicians playing in events and functions in order to formulate a professional perspective. A pilot project on an improved music education curriculum that could be tested in primary schools in Uganda would provide guidance on how music education could be delivered effectively in Uganda and on the most suitable ways of providing practical music training to locals. A study specifically focusing on social aspects and feelings of social inclusion should also be conducted.

\section{Implications for practice and further research}

The current study highlighted a significant need for further research and for practical improvements for music education practice in Uganda. It became evident that music education has been sidelined by other school subjects and that there is a significant need for further research in:

- A suitable, improved music education curriculum for primary schools in Uganda;

- Additional and improved resources for teaching music in primary school;

- Effective methods for training teachers in music at primary school level; and

- A more comprehensive understanding of how music intervention could enhance feelings of social inclusion and belonging in the young.

In practice, teacher training colleges should encourage teachers to include music in their practice. Teacher trainers need to highlight the importance of music in the school curriculum to teachers and to encourage them to teach it alongside other subjects. Teachers should be informed of music resources and how they can access them. Most importantly, they should 
gain an understanding of how practical musical skills can help the young with seeking employment and, therefore, prevent them from becoming unemployed and falling into poverty whilst enhancing their feelings of social inclusion and belonging.

\section{References}

Atkinson, A. B. \&Marlier, E. (2010). Analysing and Measuring Social Inclusion in a Global Context. United Nations.

Awiti, A. (2016). The Uganda Youth Survey Report. Retrieved June 14, 2018 from http://ecommons.aku.edu/eastafrica_eai/18.

Bandiera, O., Buehren, N., Burgess, R., Goldstein, M., Gulesci, S., Rasul, I. \& Suliman, M. (2012). Empowering Adolescent Girls: Evidence from a Randomized Control Trial in Uganda. Retrieved on July 25, 2018 from https://pdfs.semanticscholar.org/8d35/ac20ac1d3aa4c23852a1201cc01188ce19e2. pdf.

Baumeister, R. F., DeWall, C. N., Ciarocco, N. \& Twenge, J. (2005). 'Social Exclusion Impairs Self-regulation'. Journal of Personality and Social Psychology, 88 (4),589-604.

Beidel, D., Turner S. \& Morris T. (1995). 'A New Inventory to Assess Childhood Social Anxiety and Phobia. The Social Phobia and Anxiety Inventory for Children'. Psychological Assessment, 1,73-79.

Byabashaija, W. (2011). 'The Impact of College Entrepreneurial Education on Entrepreneurial Attitudes and Intention to Start a Business in Uganda'. Journal of Developmental Entrepreneurship, 16, 127-135.

Bongomin, G. O. C., Munene, J. C., Mpeera, J. T. \&Akol, C. M. (2017). 'Financial Inclusion in Rural Uganda: The Role of Social Capital and Generational Values'. Cogent Business \& Management, 4 (1). Retrived on June 10, 2018 from https://www.tandfonline.com/doi/full/10.1080/23311975.2017.1302866.

Cooke, P. (1997). Peter Cooke Uganda Collection. Retrieved on June 14, 2018 from http://sounds.bl.uk/world-and-traditional-music/peter-cooke-uganda.

Crick, N. R. \& Ladd, G. W. (1993). 'Children's Perceptions of their Peer Experiences: Attributions, Loneliness, Social Anxiety and Social Avoidance'. Developmental Psychology, March, 29 (2), 244-254.

Dennis, I. \&Guio, A.-C. (2003). Poverty and Social Exclusion in the EU after Laeken-Parts: part 1 and 2. Eurostats, Luxemburg. Retrieved on July 12, 2018 from http://epp.eurostat.ec.europa.eu/cache/ITY_OFFPUB/KS-NK-04-016/EN/KSNK-04016-EN.

European Commission (2003). Joint Report on Social Inclusion. Retrieved on July 12, 2010 from from http://ec.europa.eu/employment_social/soc-prot/socincl/joint_rep_en.htm.

Frederickson, N. L. \& Furnham, A. F. (2001). 'The Long-term Stability of Sociometric Status Classification: A Longitudinal Study of Included Pupils who Have Moderate Learning 
Difficulties and their Mainstream Peerp'. Journal of Child Psychology and Psychiatry and Allied Disciplines, 42 (5), 581-592.

Gazemba, S. (2015). 'Popular Music in Uganda'. Music in Africa Magazine. Retrieved on June 14, 2018 fromhttps://www.musicinafrica.net/magazine/popular-music-uganda.

Gestrich, A. and Raphael, L. (eds.) (2007). Inklusion, Exklusion: StudienzuFremdheit und Armut von der Antike bis zurGegenwart. Lang Publishers.

Kigozi, B. (2008). An evaluation of Music Education in Elementary Schools in Buganda: a Way Forward. A PhD Thesis from the University of Pretoria. Retrieved online September 18, 2018 , from http://repository.up.ac.za/bitstream/handle/2263/27984/Complete.pdf?sequence=9

Kigozi, B. (2015). Music Education in Uganda. Music in Africa. Retrieved online February 11, 2019, from https://www.musicinafrica.net/magazine/music-education-uganda

Kyeyune, R. (2015). Teacher Preparation and Continuing Professional Development in Africa (TPA). Retrieved on July 13, 2018, from http://www.sussex.ac.uk/cie/projects/completed/tpa/uganda.

Lakuma, C. P., Marty, R. \&Kuteesa, A. (2016). 'Survival Analysis of Regional Unemployment in Uganda: Evidence from the Uganda National Panel Survey (UNPS)'. African Development Review, 28 (1), 140-154.

Leary, M., Kelly, K.M., Cottrell, C.A. \&Schreindorfer, L.S. (2005). Individual Differences in the Need to Belong: Mapping the Nomological Network. Duke University.

MacDonald, G. \& Leary, M. (2005). 'Why Does Social Exclusion Hurt? The Relationship between Social and Physical Pain'. Psychological Bulletin, 131(2), 202-223.

Molden, D., Lucas, G., Gardner, W., Dean, K. \& Knowles, M. (2009). 'Motivations for Prevention or Promotion Following Social Exclusion: Being Rejected versus Being Ignored'. Journal of Personality \& Social Psychology, 96 (2), 415-431.

Namuggala, V. F. (2017a). 'Improving Employment Opportunities for Formerly Displaced Youth in Northern Uganda'.IDS Policy Briefing 140. IDS.

Namuggala, V. F. (2017b). 'Gambling, Dancing, Sex Work: Notions of Youth Employment in Uganda'. Africa's Youth Employment Challenge: New Perspectives, 48 (3).

Nasasira, B. (2016). 'Why Uganda's Music Industry is at a Collapse'.Newslex Point Newspaper. Retrieved on June 14, 2018 fromhttp://newslexpoint.com/collapseugandas-music-industry/.

Natuhwera, A. (2015). 'Traditional Music in Uganda'. Music in Africa Magazine. Retrieved on July 15, 2018 from https://www.musicinafrica.net/magazine/traditional-music-uganda.

Poggi, A. (2003). Measuring Social Exclusion Using the Capability Approach.UniversitatAutonoma de Barcelona.

Propa, J. (2015). 'Opportunities for Musicians in Uganda'. Music in Africa Magazine. Retrieved on July 15, 2018 fromhttps://www.musicinafrica.net/magazine/opportunitiesmusicians-uganda. 
Rinta, T., Purves, R., Welch, G., Stadler Elmer, S. \&Bissig, R. (2011). 'Connections between Children's Feelings of Social Inclusion and their Musical Backgrounds'. Journal of Social Inclusion, 2 (2), 34-57.

RintaTettey, T. (2018). Music Education in Uganda: Empirical Study on Current Practices and a Way Forward. Retrieved on July 15, 2018 from. https://www.researchgate.net/project/Music-teacher-training-in-Kampala-Uganda.

Solomon, Thomas (2015). African Musics in Contexts - Institutions, Culture, Identity. Fountain Publishers.

Ssempebwa, J. (2006). 'Graduate Unemployment in Uganda: Socioeconomic Factors Exonerating University Training'. Proceedings of the First Graduate Conference on Research and Dissemination of Findings, 28 August 2006.

Taremwa, J. (2017). 'Investing in Youth Through TVET: an Alternative Solution to Child Trafficking and Pro-growth Strategies in Uganda'. Africa Journal of Technical and Vocational Education and Training, 2 (1), 15-24.

Tisdall, E. K. M., Davis, J. M., Hill M. \&Prout, A. (Eds.) (2006). Children, young people and social inclusion: Participation for what? Bristol.

Twenge, J., Baumeister R.; DeWall C., Ciarocco N. and Bartels J. (2007). 'Social Exclusion Decreases Prosocial Behavior'. Journal of Personality and Social Psychology, 92 (1), 56-66.

Uganda Bureau of Statistics (2016). Labour Market Transition of Young People in Uganda Highlights of the School-to-Work Transition Survey 2015. Retrieved on June 14, 2018, from

http://www.ubos.org/onlinefiles/uploads/ubos/pdf\%20documents/Labour\%20Market \%20Transition\%20of\%20Young\%20People\%20in\%20Uganda_SWTS\%202015.pdf.

UN (United Nations) (2018). Identifying Social Inclusion and Exclusion. Retrieved on March 15, 2018 from http://www.un.org/esa/socdev/rwss/2016/chapter1.pdf.

UNESCO (2010). Education for All. Retrieved on March 15, 2018 from www.unesco.org/en/efa/the-efa-movement/.

\section{Biographical notes}

Doctor Tiija Rinta is an educationist, researcher and development worker based in London, UK. She is based at the Institute of Education (University of London), working for research projects concerned with music, social science and education. Tiija has worked for several international NGOs, Government Agencies and universities in the above roles. Her recent work has included developing teaching and learning materials for UNICEF, Save the Children and Relief International, as well as carrying out research for the European Union and the UK Government. The products of these projects are publications in international professional journals, articles in magazines and book chapters. 